\title{
Research on Maximal Covering Problem Based on Cost and Customer Satisfaction Degree
}

\author{
Xiuyan Wang*, Ying Qu and Chunyou Wu \\ Faculty of Management and Economics, Dalian University of Technology, Dalian, Liaoning Province 116024, PR China \\ ${ }^{*}$ Corresponding author
}

\begin{abstract}
According to cost and customer satisfaction degree, we build a bi-objective maximal covering problem in order to study the influence of central station siting by cost and customer satisfaction degree. During solving this bi-objective maximal covering problem, we use the normalized normal constraint method owing to cost and customer satisfaction degree having different dimensions. Finally, taking Shandong waste electronics recycling as an example, we code and solve by CPLEX, and analyzed the results.
\end{abstract}

Keywords-customer satisfaction; cost; maximal covering problem; service center; service center; the normalized normal constraint method

\section{INTRODUCTION}

In the fierce market competition, the quality of enterprise service has become a key factor to merits the success of enterprise logistics. "Close to customer" has appeared when enterprise development marketing strategies, thus the customer satisfaction has been unprecedented attention. Because the customer satisfaction not only plays a key role to development marketing strategies, but also improve the comprehensive competitiveness of enterprises (Angilella et al.,2014 ; Szymanski et al., 2001 ). Now, many companies adopt a variety of strategies to measure customer satisfaction in order to meet customer needs and analyzing the company's current marketing strategy is appropriate (Fornell et al., 2006). $\mathrm{Ma}$ (2005) presents that service facility siting and distribution route choice play a key role to maximize customer satisfaction. When enterprise introduces time satisfaction to location problem, it can help enterprise to lay the foundation to establish an effective mechanism and optimally limited resources, and then keeping the location goals and corporate Strategy consistency.

There are two streams of literature concerning this study. One stream is about customer satisfaction. Subramanian et al.(2014) study the Chinese electronics retail customer satisfaction and competition based on SEM model, and provide the basis for enterprises to develop marketing strategies to meet the growing customer needs and government regulation of electronic retailing. Chow et al.(2014) research customer satisfaction and quality service of Chinese aviation industry and analysis the main factors affecting customers satisfaction and how to improve the quality service of aviation industry. Terpstra et al. (2013) present that customer service costs and customer value pay a positive correlation to customer satisfaction based on the financial services sector experience data. Overall, the above study focused on customer satisfaction how to impact on business marketing strategies and provide decision-making to government to improve service, however, those study did not consider the cost of customer satisfaction.

The second stream is about maximal covering problem. Wang et al.(2006) established a logistics distribution center location model based on modifying alternative expenses and time and solving this model by heuristic algorithm. Ma et al. (2006) defined the time satisfaction and presented the timesatisfaction-based maximal covering location problem, and provided a heuristic algorithm based on Lagrangian relaxation to solve this problem. Yang et al(2013), Mahdi et al.(2013) and Sim et al.(2009) established risk aversion P-hub model, fuzzy P-hub model to solve minimize transport time and r-allocation P-hub model. However, the study above only reached the cost and ignored the customer satisfaction.

In summary, this paper established P-hub model considering cost and customer satisfaction, and token recycling waste engine in Shangdong a case. The normalized normal constraint method was used to solve the P-hub problem considering the different dimensions.

\section{MODEL INTRODUCTION}

\section{A. Notes}

$j$ : alternative recycling center, $j \in\{1,2, \cdots, M\}$;

$i$ : the i-th recycling center, $i \in\{1,2, \cdots, N\}$;

$G$ : the alternative recycling center is needed to select from the number of recycling centers, the $G$ is 3 in this paper;

$k_{j}$ : the disposal costs per unit of product of alternative recycling center $j$ ( such as storage costs);

$f_{j}$ : establishment costs of alternative recycling center $j$;

$c_{i j}$ : recycling fee per unit of product from alternative recycling center $j$ to recycle bin $i$;

$c_{m j}$ : recycling fee per unit of product from alternative recycling center $j$ to recycling center;

$r_{i}$ : the recovery amount of recycle bin $i$;

$r_{m j}$ : the recovery amount from alternative recycling center $j$ to recycling center; 
$t_{s j}$ : the operation time of alternative recycling center $j$;

$t_{i j}$ : the recovery time per unit used product from alternative recycling center $j$ to recycle bin $i$;

$t_{m j}$ : the recovery time per unit used product from alternative recycling center $j$ to recycling center;

$f$ : the customer time satisfaction function ;

$U_{i}$ : customer could receive the minimum waiting time about recycling bin $i$ when he feels very dissatisfied;

$X_{i j}=\left\{\begin{array}{l}1 \text { the recycle bin } i \text { chooses alternative recycling center } j ; \\ 0 \quad \text { otherwise. }\end{array}\right.$ $y_{j}= \begin{cases}1 & \text { alternative recycling center is choosed as center } \\ 0 & \text { otherwise }\end{cases}$

According to (Karasakal et al.,2004), the customer time satisfaction function is as follows:

$$
S_{i j}= \begin{cases}1 & \text { if } t_{i j} \leq U_{i} \\ f\left(t_{i j}\right) & \text { if } U_{i} \leq t_{i j}\end{cases}
$$

In this paper, we use sigmoid function to measure customer satisfaction function:

$$
f\left(t_{i j}\right)= \begin{cases}1 & \text { if } t_{i j} \leq U_{i} ; \\ \frac{2 e^{-\beta\left(t_{i j}-U_{i}\right)}}{1+e^{-\beta\left(t_{i j}-U_{i}\right)}} & \text { if } U_{\mathrm{i}}<t_{i j} ;\end{cases}
$$

Where $\beta$ is positive time-sensitive factor.

\section{B. Model}

$$
\begin{array}{r}
\min _{x_{i j}, y_{j}} \sum_{i=1}^{N} \sum_{j=1}^{M} c_{i j} x_{i j} r_{i}+\sum_{j=1}^{M} c_{m j} y_{j} r_{m j}+\sum_{j=1}^{M} k_{j} y_{j} r_{m j}+\sum_{j=1}^{M} f_{j} y_{j} \\
\max _{x_{i j}, y_{j}} \sum_{i=1}^{N} \sum_{j=1}^{M} f\left(t_{i j}\right) x_{i j}+\sum_{j=1}^{N} f\left(t_{s j}\right) y_{j}+\sum_{j=1}^{N} f\left(t_{m j}\right) y_{j}
\end{array}
$$

Constraints:

$$
\begin{gathered}
x_{i j} \leq x_{j j} \quad \forall j \in M, \forall i \in N \\
\sum_{j=1}^{M} x_{i j}=1 \quad \forall i \in N \\
y_{j} r_{m j}=\sum_{i=1}^{M} x_{i j} r_{i} \quad \forall j \in M, \forall i \in N
\end{gathered}
$$

$$
\begin{array}{lc}
r_{i}^{t} \geq 0 & \forall i \in N, \forall t \in T \\
& \sum_{j=1}^{N} x_{j j}=G \\
x_{i j} \in\{0,1\} & \forall j \in M, \forall i \in N \\
y_{j} \in\{0,1\} & \forall j \in M, \forall i \in N
\end{array}
$$

The objective functions (1) and (2) respectively represent the minimum cost and maximize customer satisfaction time. Constraints from (3) to (7) respectively represent the recycling center could recycle the waste products when alternative recycling centers is selected as a recycling center, one recycle bin only belonging to one recycling centers, the amount of recycling center should be equal to the sum of the number of trash recycling of waste products, amount of recovery is greater than zero, the number of recycling centers need to select.

To facilitate solving, the objective functions (2) can be changed to (2a).

$$
\min _{x_{i j}, y_{j}} \sum_{i=1}^{N} \sum_{j=1}^{M}-f\left(t_{i j}\right) x_{i j}-\sum_{j=1}^{N} f\left(t_{s j}\right) y_{j}-\sum_{j=1}^{N} f\left(t_{m j}\right) y_{j}
$$

\section{THE NORMALIZED NORMAL CONSTRAINT METHOD}

The normalized constraint method is divided into seven steps:

Setp-1: Anchor. The optimal solution $\mu^{1^{*}}$ and $\mu^{2^{*}}$ by solving the problems (1) and (2), and connecting these two points, then the utopia line is got, see it in Fig1.

Setp-2: Normal. In order to avoid different scales and solving optimization problems, the space should be normed. The specific process is as follows:

Let

$$
\begin{aligned}
\mu^{u} & =\left[\mu_{1}\left(x^{1^{*}}\right), \mu_{2}\left(x^{2^{*}}\right)\right]^{T} \\
l_{1} & =\mu_{1}\left(x^{2^{*}}\right)-\mu_{1}\left(x^{1^{*}}\right) \\
l_{2} & =\mu_{2}\left(x^{1^{*}}\right)-\mu_{2}\left(x^{2^{*}}\right)
\end{aligned}
$$

Then, the normal space is as follow(see it in Fig2):

$$
\bar{\mu}=\left\{\frac{\mu_{1}(x)-\mu_{1}\left(x^{1^{*}}\right)}{l_{1}}, \frac{\mu_{2}(x)-\mu_{2}\left(x^{2^{*}}\right)}{l_{2}}\right\}
$$

(1) 


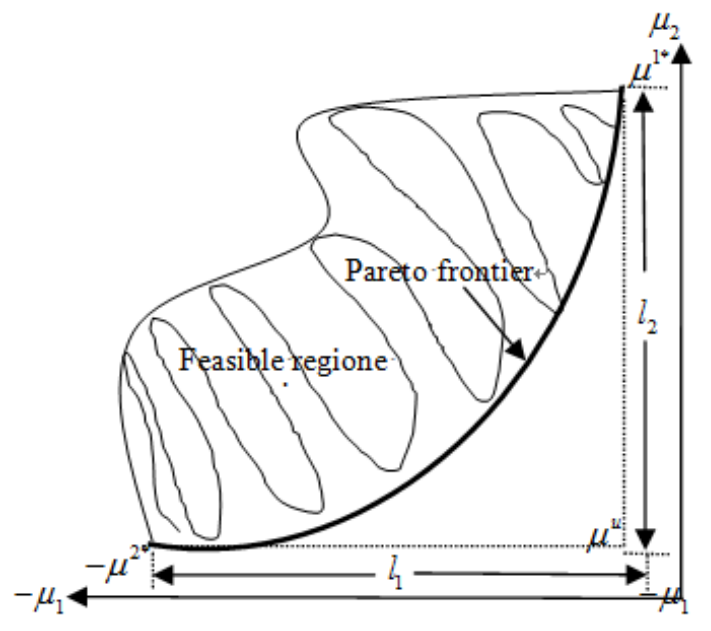

FIGURE I.

GENERAL DESIGN METRIC SPACE

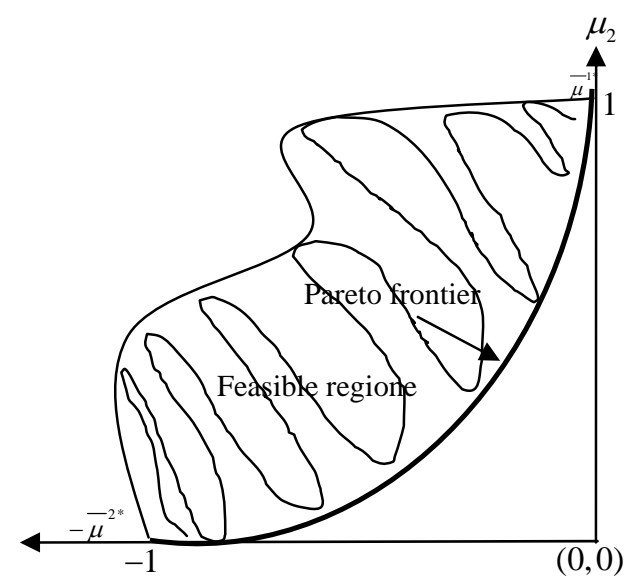

FIGURE II.

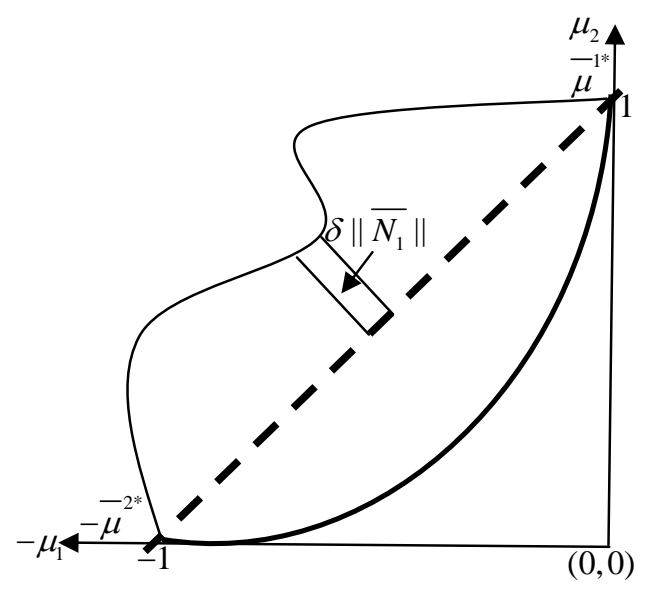

FIGURE III.

FIG.3 A SET POINTS ON THE UTOPIA LINE FOR $\bar{\mu}_{2}$
Setp-3:direction select. $\overline{N_{1}}$ is the direction from $\bar{\mu}^{1^{*}}$ to $\bar{\mu}^{2^{*}}$,

i.e. $\overline{N_{1}}=\bar{\mu}^{2^{*}}-\bar{\mu}^{1^{*}}=[1,-1]$.

Setp-4:points select. Get incremental $\delta_{1}$ in standard space and the incremental direction is $\overline{N_{1}}$, generally, $\delta_{1}=\frac{1}{m_{1}-1}\left(m_{1}\right.$ is integer). see it in Fig3.

Setp-5:Generate more anchors according to the direction and increment. The method is as follows:

$\overline{X_{p j}}=\alpha_{1 j} \bar{\mu}^{1^{*}}+\alpha_{2 j} \bar{\mu}^{2 *}$

where $0 \leq \alpha_{1 j} \leq 1, \sum_{k=1}^{2} \alpha_{k j}=1, j \in\left\{1,2, \cdots, m_{1}\right\}$

generally, $\alpha_{k j}$ is $\delta_{1}$.

Setp-6:Generate Pareto points. The Pareto points can get through the following optimization problems:

$\min _{x} \bar{\mu}_{2}$

s.t.

$$
\begin{gathered}
g_{j}(x) \leq 0 \quad(1 \leq j \leq r) \\
h_{k}(x)=0 \quad(1 \leq k \leq s) \\
x_{l i} \leq x_{i} \leq x_{u i} \quad\left(1 \leq i \leq n_{x}\right) \\
\bar{N}_{1}\left(\bar{\mu}-\bar{X}_{p j}\right)^{T} \leq 0 \\
\bar{\mu}=\left\{\bar{\mu}_{1}(x), \bar{\mu}_{2}(x)\right\}
\end{gathered}
$$

Setp-7:Solving optimal value in non-standardized space. The optimal value can be got through the following relation:

$$
\mu=\left[\bar{\mu}_{1} l_{1}+\mu_{1}\left(x^{1^{*}}\right) \quad \overline{\mu_{2}} l_{2}+\mu_{2}\left(x^{2^{*}}\right)\right]
$$

\section{CASE STUDY}

\section{A. Data Preparation}

This paper takes used engine as an example in Shangdong. The used engine is handle in Jinan, and there are 15 recycle bins in Shandong(see Table 1). The 6 recycling bins among the 15 regards as potential service center(see Table 2), and 3 recycling bins are choosed as recycling centry.

TABLE I. THE NAME OF RECYCLE BIN IN SHANDONG PROVINCE

\begin{tabular}{|c|c|c|}
\hline $\begin{array}{c}\text { 1. recycle bin of } \\
\text { Longkou }\end{array}$ & 2. recycle bin of yantai & $\begin{array}{c}\text { 3. recycle bin of } \\
\text { Weifang }\end{array}$ \\
\hline 4. recycle bin of rizhao & $\begin{array}{c}\text { 5. recycle bin of } \\
\text { dongying }\end{array}$ & 6. recycle bin of jining \\
\hline $\begin{array}{c}\text { 7. recycle bin of } \\
\text { boxing }\end{array}$ & 8. recycle bin of zibo & $\begin{array}{c}\text { 9. recycle bin of } \\
\text { zaozhuang }\end{array}$ \\
\hline $\begin{array}{c}\text { 10. recycle bin of heze } \\
\text { 13. recycle bin of } \\
\text { liaocheng }\end{array}$ & $\begin{array}{c}\text { 11. recycle bin of } \\
\text { yanzhou }\end{array}$ & $\begin{array}{c}\text { 12. recycle bin of } \\
\text { laiyang }\end{array}$ \\
\hline
\end{tabular}


TABLE II. POTENTIAL SERVICE CENTER BEING CHOOSED

\begin{tabular}{|l|l|l|}
\hline 1. recycle bin of yantai & 2. recycle bin of jining & 3. recycle bin of boxing \\
\hline $\begin{array}{l}\text { 4. recycle bin of } \\
\text { yanzhou }\end{array}$ & $\begin{array}{l}\text { 5. recycle bin of } \\
\text { laiyang }\end{array}$ & $\begin{array}{l}\text { 6. recycle bin of } \\
\text { qingzhou }\end{array}$ \\
\hline
\end{tabular}

TABLE III. THE DISTANCE FROM POTENTIAL SERVICE CENTER TO RECYCLE BIN (KILOMETER)

\begin{tabular}{|c|c|c|c|c|c|c|}
\hline No. & 1 & 2 & 3 & 4 & 5 & 6 \\
\hline 1 & 100 & 280 & 130 & 270 & 70 & 120 \\
\hline 2 & 0 & 300 & 180 & 290 & 100 & 160 \\
\hline 3 & 120 & 200 & 100 & 190 & 100 & 50 \\
\hline 4 & 170 & 140 & 155 & 130 & 110 & 120 \\
\hline 5 & 170 & 210 & 50 & 200 & 125 & 50 \\
\hline 6 & 300 & 0 & 170 & 40 & 250 & 170 \\
\hline 7 & 180 & 170 & 0 & 160 & 135 & 50 \\
\hline 8 & 180 & 150 & 60 & 130 & 126 & 28 \\
\hline 9 & 300 & 70 & 190 & 60 & 250 & 180 \\
\hline 10 & 350 & 60 & 200 & 70 & 300 & 170 \\
\hline 11 & 290 & 40 & 160 & 0 & 240 & 150 \\
\hline 12 & 100 & 250 & 135 & 240 & 0 & 110 \\
\hline 13 & 300 & 85 & 130 & 110 & 240 & 130 \\
\hline 14 & 160 & 170 & 50 & 150 & 110 & 0 \\
\hline 15 & 60 & 300 & 200 & 300 & 100 & 180 \\
\hline
\end{tabular}

TABLE IV. THE TIME FROM POTENTIAL SERVICE CENTER TO RECYCLE BIN (HOUR)

\begin{tabular}{|c|c|c|c|c|c|c|}
\hline No. & 1 & 2 & 3 & 4 & 5 & 6 \\
\hline 1 & 4.5 & 10 & 7 & 10 & 5 & 6 \\
\hline 2 & 0 & 11 & 8 & 11 & 5 & 7 \\
\hline 3 & 6 & 8 & 5 & 8 & 5 & 4.5 \\
\hline 4 & 7.5 & 7 & 7.5 & 7 & 6 & 6.5 \\
\hline 5 & 7.5 & 8.5 & 5 & 8 & 9 & 6.5 \\
\hline 6 & 11 & 0 & 7.5 & 4 & 10 & 7.5 \\
\hline 7 & 8 & 7.5 & 0 & 7.5 & 7 & 5 \\
\hline 8 & 7.5 & 7 & 4 & 6.5 & 6.5 & 4 \\
\hline 9 & 11 & 5 & 8 & 5 & 9.5 & 7.5 \\
\hline 10 & 12 & 5 & 8 & 5 & 10.5 & 8 \\
\hline 11 & 11 & 4 & 7.5 & 0 & 9.5 & 7.5 \\
\hline 12 & 5 & 10 & 7 & 9.5 & 0 & 7.5 \\
\hline 13 & 10 & 6 & 7 & 6 & 9 & 7 \\
\hline 14 & 7 & 7.5 & 5 & 7.5 & 7.5 & 0 \\
\hline 15 & 5 & 11.5 & 9 & 11 & 11 & 8 \\
\hline
\end{tabular}

TABLE V. THE UNIT COST OF HANDLING IN THE POTENTIAL SERVICE CENTER(YUAN)

\begin{tabular}{|c|c|c|c|c|c|c|}
\hline No. & 1 & 2 & 3 & 4 & 5 & 6 \\
\hline fee & 120 & 90 & 55 & 70 & 100 & 70 \\
\hline
\end{tabular}

TABLE VI. THE UNIT COST OF TRANSPORTATION FROM ALTERNATIVE RECYCLING CENTER TO RECYCLING CENTER(YUAN)

\begin{tabular}{|c|c|c|c|c|c|c|}
\hline No. & 1 & 2 & 3 & 4 & 5 & 6 \\
\hline fee & 75 & 80 & 75 & 120 & 110 & 90 \\
\hline
\end{tabular}

TABLE VII. THE SETUP COST OF POTENTIAL SERVICE CENTER(YUAN)

\begin{tabular}{|c|c|c|c|c|c|c|}
\hline No. & 1 & 2 & 3 & 4 & 5 & 6 \\
\hline fee & 11000 & 12000 & 15000 & 13000 & 11500 & 10000 \\
\hline
\end{tabular}

TABLE VIII. THE OPERATION TIME OF POTENTIAL SERVICE CENTER(HOUR)

\begin{tabular}{|c|l|l|l|l|l|l|}
\hline No. & 1 & 2 & 3 & 4 & 5 & 6 \\
\hline fee & 2 & 3 & 5 & 5 & 4 & 4 \\
\hline
\end{tabular}

TABLE IX. THE TRANSPORTATION TIME FROM ALTERNATIVE RECYCLING CENTER TO RECYCLING CENTER (HOUR)

\begin{tabular}{|c|c|c|c|c|c|c|}
\hline No. & 1 & 2 & 3 & 4 & 5 & 6 \\
\hline time & 9 & 6 & 5 & 5.5 & 5.5 & 5 \\
\hline
\end{tabular}

\section{B. Solving}

This paper solved this problem by matlab(R2012a,64 -bit). The optimal is as follows:

TABLE $\mathrm{X}$. OPTIMAL VALUES OF DIFFERENT PARAMETERS

\begin{tabular}{|c|c|c|c|c|c|}
\hline $\mathrm{A}$ & $29 \alpha$ & $\begin{array}{c}\text { the optimal } \\
\text { location }\end{array}$ & $\begin{array}{c}\text { the optimal } \\
\text { values of } \\
\mu_{1}(x)\end{array}$ & $\begin{array}{c}\text { the optimal } \\
\text { values of } \\
\mu_{2}(x)\end{array}$ & $\begin{array}{l}\text { the } \\
\text { optimal } \\
\text { values of } \\
\bar{\mu}_{2}(x)\end{array}$ \\
\hline \multirow{6}{*}{0.1} & 1 & Fig.4 & 44347 & -18.5094 & 0.999998 \\
\hline & $2-4$ & Fig.5 & 46970 & -18.5141 & 0.944727 \\
\hline & $5-11$ & Fig.6 & 46106 & -18.5221 & 0.852335 \\
\hline & $\begin{array}{c}12- \\
13\end{array}$ & Fig.7 & 48521 & -18.5435 & 0.604159 \\
\hline & $\begin{array}{c}14- \\
16\end{array}$ & Fig.8 & 46354 & -18.5499 & 0.530672 \\
\hline & $\begin{array}{l}17- \\
28\end{array}$ & Fig.9 & 45458 & -18.5599 & 0.414053 \\
\hline \multirow{2}{*}{0.3} & $1-9$ & Fig.4 & 44347 & -14.2916 & 1.000001 \\
\hline & $\begin{array}{l}10- \\
28\end{array}$ & Fig.10 & 45415 & -14.2999 & 0.671382 \\
\hline \multirow{4}{*}{0.5} & $1-2$ & Fig.10 & 45415 & -14.4632 & 0.98419 \\
\hline & $3-5$ & Fig.11 & 44551 & -14.4732 & 0.90155 \\
\hline & $6-7$ & Fig.9 & 45458 & -14.4823 & 0.82634 \\
\hline & $8-28$ & Fig.6 & 45490 & -14.4922 & 0.74371 \\
\hline & 1 & Fig.4 & 44347 & -9.18438 & 0.999996 \\
\hline & $2-4$ & Fig.10 & 45415 & -9.18942 & 0.952022 \\
\hline
\end{tabular}




\begin{tabular}{|c|c|c|c|c|c|}
\hline 0.7 & $5-8$ & Fig.11 & 44551 & -9.20032 & 0.848129 \\
\cline { 2 - 6 } & 9 & Fig.15 & 45787 & -9.21571 & 0.701458 \\
\cline { 2 - 6 } & & & & & \\
\hline $10-$ & Fig.12 & 46022 & -9.21779 & 0.681657 \\
\cline { 2 - 6 } & & & & \\
\hline $16-$ & Fig.13 & 45527 & -9.24209 & 0.449985 \\
17 & & & & \\
\hline & $18-$ & Fig.14 & 46595 & -9.24713 & 0.402011 \\
28 & & & & \\
\hline
\end{tabular}

notes: $\mu_{1}(x)$ is the objective functions(1), $\mu_{2}(x)$ is the objective functions(2a)

\section{Result analysis}

(1)The optimal solution of iterative point of $2-16$ is inadvisable comparing with iterative point of 2-16 17-28 when $\beta$ is 0.1 , because the optimal value of iterative point of $2-16$ is more than the optimal value of iterative point of 2-16 17-28. The optimal value of $\mu_{1}(x)$ has great volatility when $\beta$ is 0.5 or 0.7 . However, the optimal value of $\mu_{2}(x)$ and is becoming smaller when No. is becoming bigger.

(2)Overall, there are 4 conditions to choose the recycling Center, the first one is :Yantai, Qingzhou, Jining; the second one is : Yantai, Qingzhou, Yanzhou; the third one is Yantai, Boxing, Jining; the last one is Yantai, Boxing, Yanzhou. (3)Volatility of Rizhao and Liaocheng is relatively large than other recycling Bin.

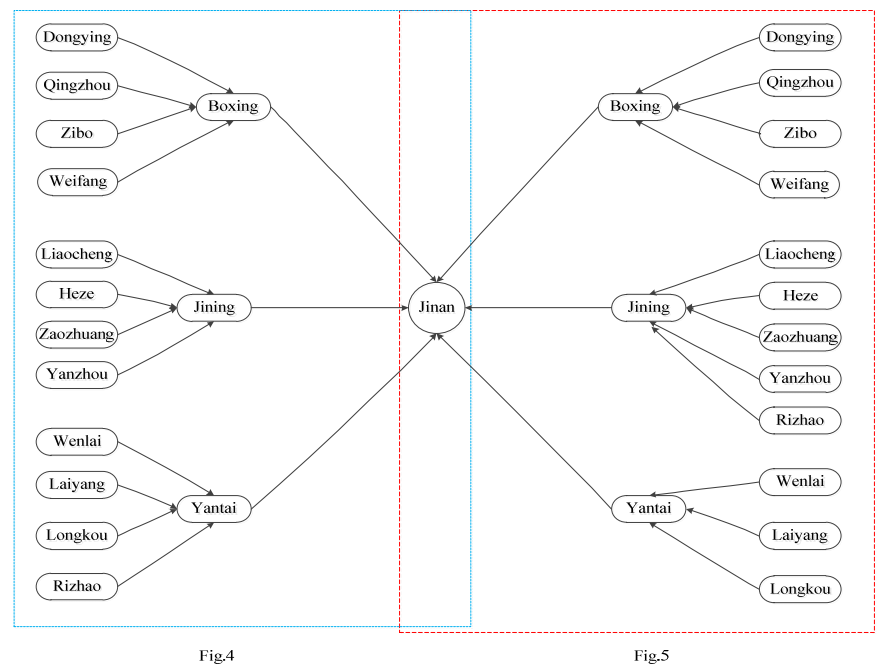

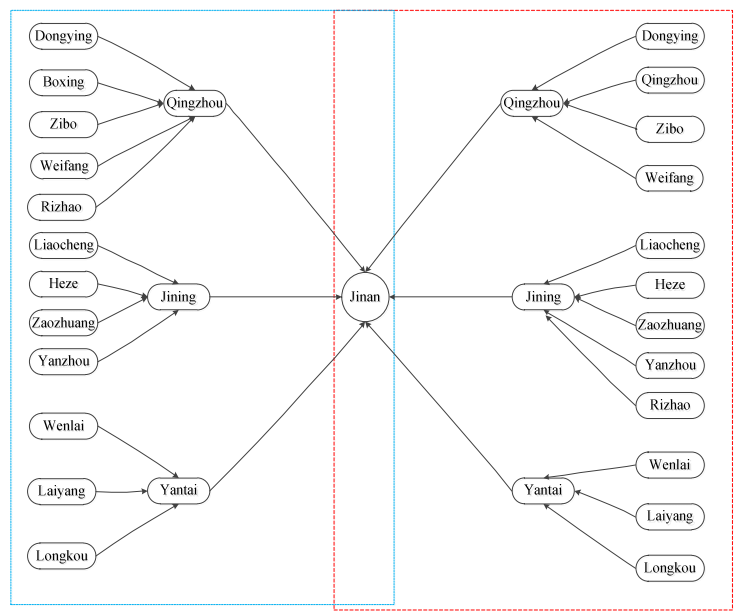

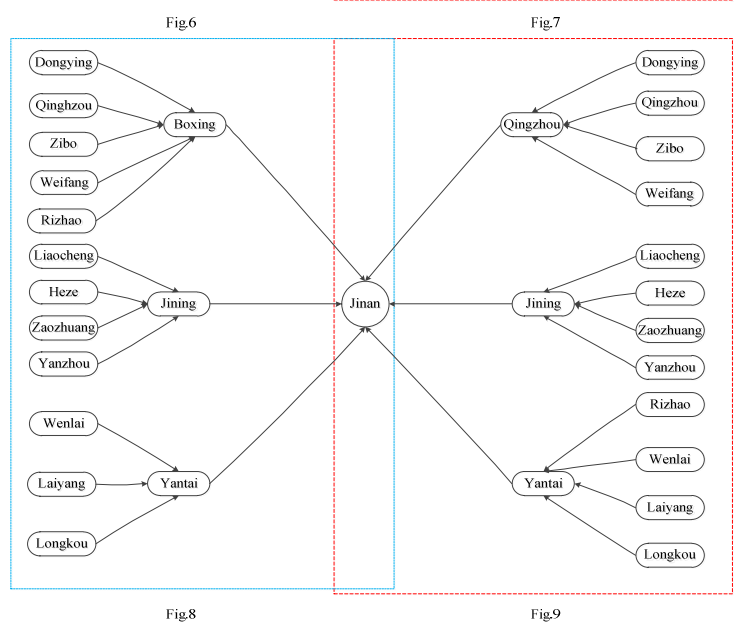

Fig. 8

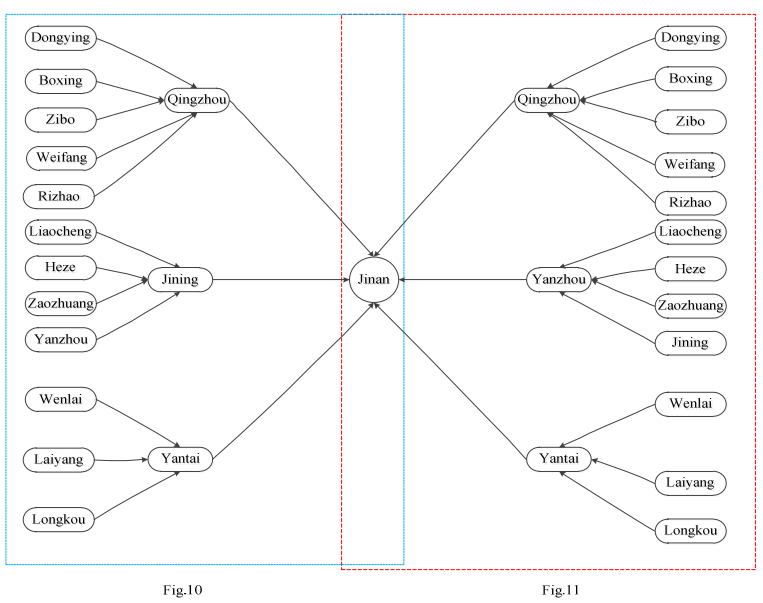




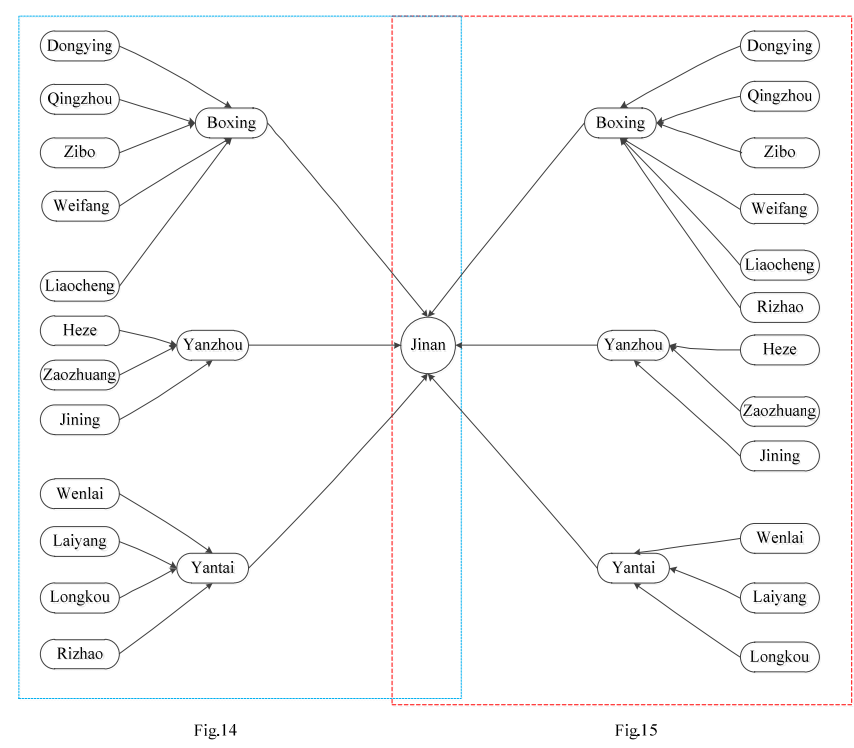

REFERENCES

[1] Angilella, Silvia, et al. MUSA-INT: Multicriteria customer satisfaction analysis with interacting criteria[J]. Omega, 2014, 42(1): 189-200.

[2] Szymanski, David M., and David H. Henard. Customer satisfaction: a meta-analysis of the empirical evidence[J]. Journal of the academy of marketing science. 2001, 29(1): 16-35.

[3] Fornell, Claes, et al. Customer satisfaction and stock prices: high returns, low risk[J]. Journal of Marketing, 2006,70(1): 3-14.

[4] Ma Yunfeng. Time-satisfaction-based covering location problem on network[D]. Wuhan, Huazhong university of science and technology, 2005.

[5] Subramanian, Nachiappan. Customer satisfaction and competitiveness in the Chinese E-retailing: Structural equation modeling (SEM) approach to identify the role of quality factors[J]. Expert Systems with Applications, 2014, 41(1): 69-80.

[6] [6]Chow, Clement Kong Wing. Customer satisfaction and service quality in the Chinese airline industry[J]. Journal of Air Transport Management, 2014, 35: 102-107.

[7] Terpstra, Maarten, and Frank HM Verbeeten. Customer satisfaction: Cost driver or value driver? Empirical evidence from the financial services industry[J]. European Management Journal,2013, inpress.

[8] Wang Xiaobo, Li Yijun. Research on logistics distribution center location model and evaluation under electronic commerce[J]. System engineering-theory methodology applications, 2006, 15(3):199-204.

[9] Ma Yunfeng, Yang Chao, Zhang Min, Hao Chunyan.Time-satisfactionbased maximal covering location problem[J].Chinese journal of management science,2006,14(2):45-51.

[10] Yang Kai, Liu Yan-Kui, Yang Guo-Qing. Solving fuzzy p-hub center problem by genetic algorithm incorporating local search[J]. Applied Soft Computing. 2013, 13(5): 2624-2632.

[11] Mahdi Bashiri, Masoud Mirzaei, Marcus Randall. Modeling fuzzy capacitated p-hub center problem and a genetic algorithm solution[J]. Applied Mathematical Modelling, 2013, 37:3513 -3525.

[12] Sim, Thaddeus, Timothy J. Lowe, and Barrett W. Thomas. The stochastic p-hub center problem with service-level constraints[J]. Computers \& Operations Research, 2009,36(12 ): 3166 -3177.

[13] Karasakal, Orhan, and Esra K. Karasakal. A maximal covering location model in the presence of partial coverage[J]. Computers \& Operations Research, 2004, 31(9): 1515-1526.

[14] Messac, Achille, Amir Ismail-Yahaya, and Christopher A. Mattson. The normalized normal constraint method for generating the Pareto frontier[J]. Structural and multidisciplinary optimization,2003, 25(2): 86-98. 